\title{
India's participation in IAU over the years
}

\author{
D. C. V. Mallik
}

Indian Institute of Astrophysics Bangalore, India

\begin{abstract}
India was still a British colony when the International Astronomical Union was born in 1919. India did not have a national science academy nor a national research council at the time. The Royal Society, London, which was the adhering body of Great Britain to IAU, handled matters of the colony too. India formally joined the IAU in 1948 as an independent nation through an initiative taken by the Government of India. In 1968, the National Institute of Sciences of India (NISI) became the adhering organisation to the IAU, as did the other affiliate Unions of ICSU. Soon after, its name was changed to Indian National Science Academy (INSA).

Till the nineteen-sixties, individual Indian membership in the IAU grew rather tardily but the situation changed with the rapid growth of astronomical activities in the country. In 1967, M.K. Vainu Bappu, the then Director of the Kodaikanal Observatory, was elected a VicePresident of the Union. In 1979, he was elected the President of IAU for the triennium 1979-1982, and during the same period, V. Radhakrishnan and Govind Swarup were elected Presidents respectively of the Commisions 34 and 40. In 1985, the General Assembly of the Union was held in New Delhi. It was dedicated to the memory of Vainu Bappu who had initiated the process of inviting the Union to hold its GA in India. A few years later the Sixth Asian-Pacific Regional IAU Meeting was held in Pune. A number of IAU symposia and colloquia have also been held in the country. During the last three decades, the engagement of the Indian astronomers with IAU has increased a great deal with a large number of them taking on important official roles in the IAU. Currently, India has close to 300 individual members.
\end{abstract}

Keywords. Indian membership in IAU

\section{Early Years: 1919-1948}

In 1919, when the International Astronomical Union was founded, India was a British colony. Although India had two major observatories carrying out work of international standard, it had no scientific academy nor a national research council through which it could join the IAU. Only three names from India feature in the first membership list of 1922 (Fowler 1922) and they are: (1) T.P. Bhaskaran, who directed the Nizamiah Observatory, Hyderabad, and was in charge of the Carte du Ciel programme in India, (2) John Evershed, Director, Solar Physics Observatory, Kodiakanal; and (3) Meghnad Saha, Professor of Physics, Allahabad University, who had published a series of papers on thermal ionization. T. Royds's name appears as a member in IAU Transactions Volume II (1925) as he became the Director in Kodaikanal when Evershed retired in 1923. John Evershed remained a prominent member of the IAU, particularly active in the solar commissions, and he continued to participate in IAU General Assemblies even after his return to England, where he set up his own solar observatory at Ewhirst, Surrey.

During the early years, the main IAU activity India participated in was the Carte $d u$ Ciel programme, which had started much before the IAU came into existence but became a part of it soon after the birth of the Union. A full commission, Commission 23, was dedicated to it. In India the programme was run by the Nizamiah Observatory 
in Hyderabad. The observatory photographed the southern zone between $17^{\circ}$ and $23^{\circ}$, originally entrusted to the Santiago Observatory, Chile which had defaulted. Later the Nizamiah Observatory also ended up doing the Potsdam zone between $36^{\circ}$ and $39^{\circ}$ north. Eventually the two zones came to be referred to as Hyderabad South and Hyderabad North zones. Under the able directorship of John Pocock, followed by that of T.P. Bhaskaran, the observatory completed in 1928 photographing the Hyderabad South zone exposing a total of 1260 plates and cataloguing 293,000 stars. From 1928 to 1937, photographs were obtained on a further 592 plates cataloguing 149,000 starts in the Hyderabad North zone.

The nineteen-twenties were a resurgent period in Indian science and the work of a number of brilliant Indian scientists was attracting international attention. Two of them, in particular, C.V. Raman and M.N. Saha, felt India should have her own science academy. In December 1930, the Government of India sent a circular (Sahni and Tandon 2017) to provincial governments, scientific departments, universities, learned societies and the Indian Science Congress Association (ISCA) seeking views on the formation of a National Research Council. The Government had decided that it was time India made a sincere effort to join the International Research Council (hereafter ICSU) and its affiliates. Since it was known to the Government that the entry to ICSU and adherence to it was preferred to be through the country's principal science academy or its national research council or through a national institution, to avoid politicisation of its activities, the Government was proposing to form a National Research Council.

The scientists in the country seized on this initiative. In March 1932, Saha established the United Provinces Academy of Sciences in Allahabad and soon after the ISCA executive started discussing the possibility of forming an all-India academy of sciences. In April 1934, C.V. Raman founded the Indian Academy of Sciences in Bangalore without the knowledge of the ISCA management and somewhat to its surprise. In January 1935, the National Institute of Sciences of India (hereinafter NISI) was created under the aegis of ISCA with its headquarters in Calcutta. From no academy at all India suddenly emerged in the international scene with three academies. The question of which one should have the official patronage was not immediately decided.

India joined ICSU in 1931 and was initially represented through the Commonwealth. After independence, India's adherence to ICSU was transferred to the Ministry of Natural Resources and Scientific Research and subsequently, to the Ministry of Education.

\section{A.V. Hill's visit: India's entry to the IAU}

During the winter of 1943-44, the noted biologist, Archibald V. Hill visited India as a representative of The Royal Society (RS) to advise on the organisation of scientific research in India and to effect its better co-ordination with scientific research in Britain. Henry Dale, President of the RS, conveyed through Hill the greetings of the RS to NISI. The NISI Council had resolved to approach the Government of India with a request to give formal recognition to it as a society representing all branches of science and accord it a status analogous to the RS in Britain and the National Academy of Sciences in the United States. This had the full support of The Royal Society, as indicated in a letter dated March 1944 from Henry Dale to Lewis Fermor, $\dagger$ the eminent geologist, one of the architects of NISI and its first President. Since India was still a British colony, there was the talk of a Royal Charter to be granted to NISI to pave the way for it to become the premier science academy of India. However, there was a resolution of the Privy Council that no Royal Charter should be granted during the period of World War II. The official process was halted. In India, steps were initiated to shift the location of NISI from Calcutta to Delhi.

$\dagger$ Henry Dale to Lewis Fermor, Royal Society Archives, courtesy The Royal Society, London. 
When the War was over, the Government of India took up the matter of obtaining a Royal Charter for NISI with the British Government. In May 1945, the headquarters of NISI had been shifted from Calcutta to Delhi. And in October 1945, the Government of India decided to recognise NISI as the premier scientific organisation of the country representing all branches of science. In 1948, at the VIIth General Assembly of the IAU in Zurich, the General Secretary, Professor Jan Oort, announced that since the previous GA, India had adhered to the Union along with Australia, Chile, the Irish Republic and Hungary (Oort 1948). The IAU records India's year of entry as 1946 and NISI as the designated adhering organisation. However, when Professor Oort wrote to the 'President of National Committee of Astronomy' (Professor Oort assumed such a body had been formed since India officially joined the Union) requesting names of individuals to whom invitations to attend the General Assembly in Zurich had to be sent, he received the following response from the Ministry of Education, Government of India, which said:

'the question of India joining the International Astronomical Union is still under consideration and that pending a decision on the question the Government of India would not be in a position to nominate any representatives to attend the forthcoming meeting of the General Assembly of the Union at Zurich in August 1948.' The letter also added: 'There is at present no National Committee in India for Astronomy.' $\dagger$

It appears, soon after the above correspondence, the matter was settled and as of August 1948, India was a full-fledged member nation of the IAU with the Government's Ministry of Natural Resources and Scientific Research acting as the adhering organisation.

There was no Indian representation at the Zurich General Assembly. However, the Government sent a list of nominations for membership which included the names of Akbar Ali, A.C. Banerji, A.K. Das, D.S. Kothari, S.K. Mitra and A.L. Narayan. The first Indian official representation to a General Assembly happened in 1952 at the VIIIth GA in Rome. A.K. Das, Director of the Kodaikanal Observatory was India's National Representative to this Congress. In 1955, at the next General Assembly in Dublin, Meghnad Saha was in attendance for the first time. Saha wrote about the Congress (Saha 1955) in third person, and I quote: 'Prof $M N$ Saha, has been a member of the $I A U$, and of a number of Commissions since the inception of the Union in 1922; but this was the first occasion he was enabled to attend due to the generous gesture of the Government of India to bear his expenses... The Government of India were too late to take the decision to send the delegation. It was not possible for the members of the delegation to meet beforehand, and plan concerted action... It is hoped that for the forthcoming session at Moscow, the Government will choose a larger delegation months ahead, name a leader and a secretary, so that the delegation gives a good show of itself and represents free India in a way befitting her dignity as a free nation.'

Saha died the following year, and the Dublin IAU was his first and last.

\section{Astronomy in independent India}

Astronomical activities in India picked up significantly in the nineteen-sixties. In 1968, Vainu Bappu (Fig. 1) established a stellar observatory in Kavalur (known today as the Vainu Bappu Observatory) which houses three major telescopes - the 1.02-m Zeiss telescope commissioned in 1972, the 2.34-m indigenously built Vainu Bappu Telescope, operational since 1986, and a 1.3-m (the J C Bhattacharyya Telescope) compact equatorial telescope with a double horseshoe mount commissioned in 2014. Radioastronomy was also started in the 1960s at the Tata Institute of Fundamental Research, under the leadership of Govind Swarup, first with a grating-type radio interferometer for observing the Sun at Kalyan near Bombay, and then with the establishment of a major radio

$\dagger$ Ministry of Education, Govt. of India, to Jan Oort, February 1948, IAU Archives. 


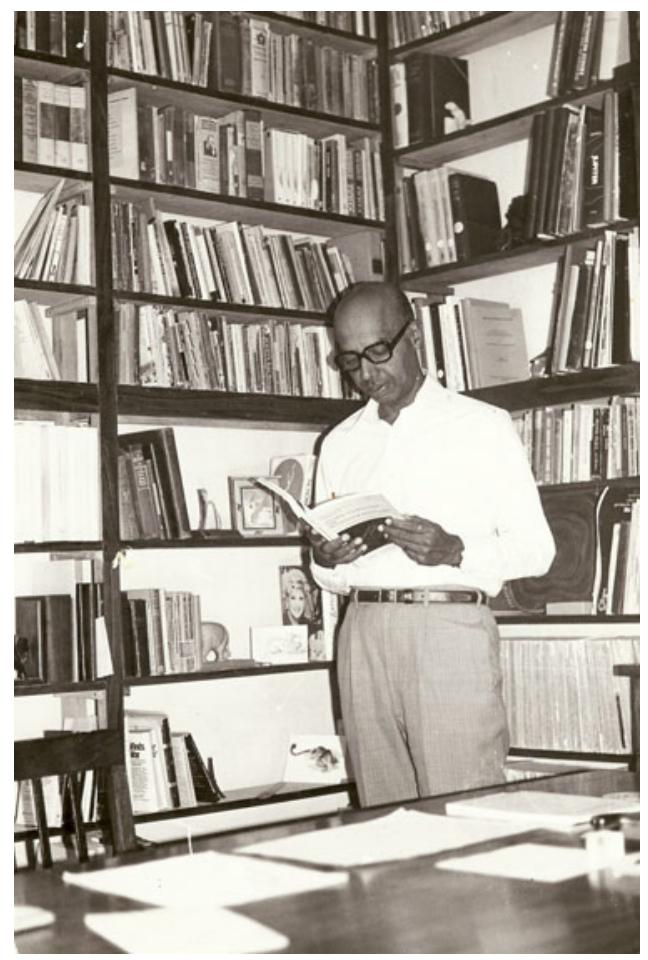

Figure 1. M. K. Vainu Bappu (1927-1982).

observatory in Ootacamund in Tamil Nadu, where in 1970 the indigenously designed and fabricated Ooty Radio Telescope was commissioned. Also in the late nineteen-sixties two more observatories acquired 1-m class telescopes, one near Hyderabad with a 1.2-m telescope and the other in Nainital, again a 1.02-m Zeiss telescope. The number of astronomers in the country increased by a large factor, which is reflected in the IAU membership from India.

Today astronomy in India has expanded further with more world-class facilities coming into operation during the last two decades. The Giant Metre Radio Telescope operated by TIFR's National Centre for Radio Astrophysics near Pune attracts astronomers from all over the world to observe the Universe at metre wavelengths. A 2-m telescope located at an altitude of 4500 metres above sea level in the trans-Himalayan deserts of Ladakh is producing high quality photometric and spectroscopic data on various astronomical objects. It is operated remotely from the newly developed Hosakote campus of the Indian Institute of Astrophysics, Bangalore.

In 2015, India launched its first fully dedicated astronomy satellite, the Astrosat, in a near-Earth orbit with instruments capable of looking at the sky in ultraviolet and x-ray wavelengths. The satellite, with an expected lifetime of five years, transmits data to the Space Department's Data Centre (ISSDC) in Bangalore. The satellite facility is open to the international community (30\% of the time). In another ten years India will join the adventure of Gravitational Wave Astronomy with a LIGO station in India in the state of Maharashtra. And some day the India-based Neutrino Observatory (INO) will also come into existence. India is a partner in the TMT Project.

A vigorous education and training programme in astronomy and astrophysics at a number of centres has resulted in an input of trained manpower to use and run these facilities. 


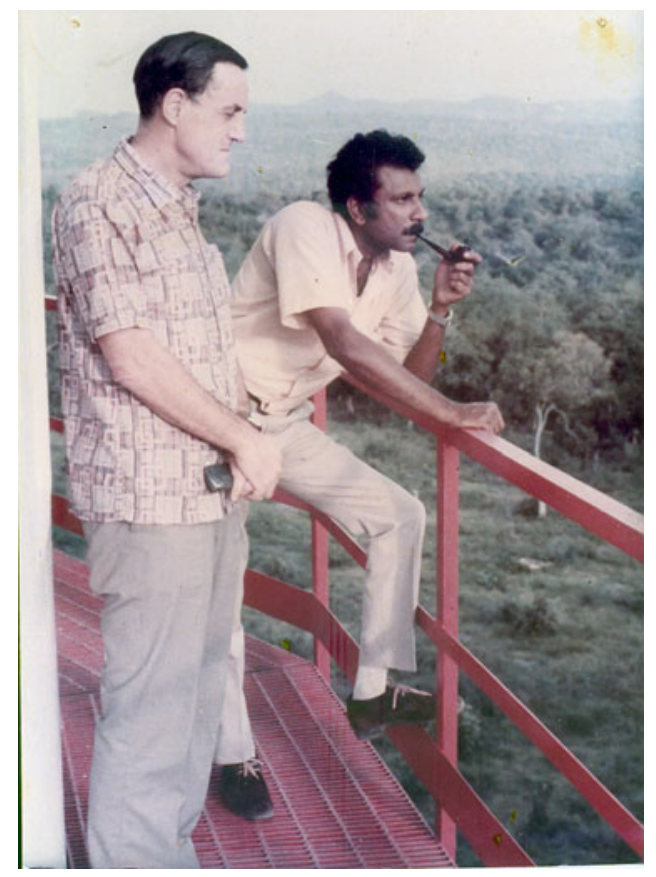

Figure 2. Hanbury Brown and V. Radhakrishnan at the catwalk of the 102-cm Zeiss telescope at Vainu Bappu Observatory.

\section{India and the IAU}

India's engagement with the IAU grew substantially in the nineteen-sixties. Vainu Bappu, who took over the directorship of Kodaikanal Observatory in 1960, is mainly responsible for enhancing the interaction of the country with the astronomical world. Through his persistent efforts the Indian National Committee for Astronomy (INCA) was formed in 1966. He was its first Secretary and later became the Chairman, 1973-1979. In 1967, Bappu was elected one of the Vice-Presidents of IAU. He was instrumental in organising the Third International School for Young Astronomers (ISYA) in Hyderabad in 1969. His dream was to invite the IAU to India to hold its General Assembly. Soon after he became the President at the Montreal IAU in 1979, he started discussing within the astronomical community in India the possibility of holding an IAU GA in the country. At the 47th meeting of the IAU Executive Committee in Amsterdam in 1980, an exploratory invitation was received from the Chairman of INCA, to hold the XIXth General Assembly in India, and the IAU Executive accepted it in principle, and anticipated that a formal invitation would be made at the XVIIIth General Assembly in Patras in 1982.

Tragedy struck India and the IAU when Vainu Bappu suddenly passed away in August 1982, just at the commencement of the Patras General Assembly. His dream was kept alive and at the closing ceremony in Patras, the formal invitation to hold the next IAU in India was read out by the Indian representative. Professor Robert Hanbury Brown, who took over as the President for the triennium 1985-1988 announced IAU's acceptance of the invitation. Professor Hanbury Brown was personally very pleased to know that he would preside over the IAU Congress in the country of his birth. It was decided to hold the Congress in New Delhi, where the required infrastructure already existed, but there was a departure from tradition. Since the climate in Delhi was known to be rather oppressive in August, the time of the Congress was shifted to November, much to the 
Table 1. Indian Officers of the IAU.

\begin{tabular}{|c|c|c|}
\hline \multicolumn{3}{|c|}{$1948-1988$} \\
\hline \multirow[t]{3}{*}{ M. K. V. Bappu } & President IAU & $1979-1982$ \\
\hline & Vice-President IAU & $1967-1973$ \\
\hline & President Commission 10 & $1973-1976$ \\
\hline \multirow[t]{2}{*}{ V. Radhakrishnan } & Vice-President IAU & $1988-1994$ \\
\hline & President Commission 34 & $1979-1982$ \\
\hline \multirow[t]{2}{*}{ G. Swarup } & President Commission 40 & $1979-1982$ \\
\hline & Last Thirty Years & \\
\hline A. K. Kembhavi & Vice-President IAU & current \\
\hline S. M. Razaullah Ansari & President Commission 41 & $1994-1997$ \\
\hline \multirow[t]{2}{*}{ J. C. Bhattacharyya } & President Commission 9 & $1991-1994$ \\
\hline & Vice-President Commission 50 & 1991-1994 \\
\hline Bimla Buti & President Commission 49 & 1991-1994 \\
\hline Sunetra Giridhar & President Commission 45 & $2006-2009$ \\
\hline R. K. Kochhar & President Commission 41 & $2012-2015$ \\
\hline J. V. Narlikar & President Commission 47 & $1994-1997$ \\
\hline \multirow[t]{2}{*}{ T. Padmanabhan } & President Commission 47 & 2009-2012 \\
\hline & Vice-President Division J & $2012-2015$ \\
\hline M. Parthasarathy & President Commission 29 & $2006-2009$ \\
\hline \multirow[t]{2}{*}{ G. Srinivasan } & President Commission 44 & $1997-2000$ \\
\hline & President Division XI & 2000-2003 \\
\hline
\end{tabular}

disappointment of the American astronomers, because the period that was chosen also included the Thanksgiving weekend.

The XIXth General Assembly of the Union was held during November 18 to 28 in New Delhi. It was inaugurated by the Prime Minister of the country, Shri Rajiv Gandhi. The Assembly was dedicated to the memory of Vainu Bappu, who had initiated the process of inviting the Union to hold its GA in India, but who did not live to see that dream come true. Professor Alan H. Batten wrote a nice report of the Congress in the Journal of RASC (Batten 1986). About 1400 members and guests attended the meeting and although the number was smaller than the General Assemblies in Europe or North America, it was considerably larger than the Sydney General Assembly in 1973. A very large number of young Indian astronomers participated in the Congress. A large fraction of them were admitted to IAU membership, in spite of some opposition from Richard West, the outgoing General Secretary at the time. A number of IAU Symposia and Colloquia were also held in the country at this time.

In 1993, the Sixth Asian-Pacific Regional IAU Meeting was held in Pune. During the last two decades, the engagement of the Indian astronomers with the IAU has grown more and more. Today the membership stands at close to 300 .

The following tables are a proof of this. Table 1 lists the names of Indian astronomers who held important official positions in the IAU. Notably only three names appear in the list during the first forty years of India's membership of the Union. During the last thirty years, the number has almost trebled. 
Table 2. IAU Meetings in India.

\begin{tabular}{|c|c|c|c|c|}
\hline Date & & Meeting & Title & Place \\
\hline Feb $19-23$ & 2018 & IAUS 340 & $\begin{array}{l}\text { Long-term Datasets for the Understanding of Solar and } \\
\text { Stellar Magnetic Cycles }\end{array}$ & Jaipur \\
\hline Jan $7-11$ & 2013 & IAUS 296 & Supernova Environmental Impacts & Kolkata \\
\hline Dec $13-16$ & 1999 & IAUC 179 & $\begin{array}{l}\text { Cyclical Evolution of Solar Magnetic Fields: Advances in } \\
\text { Theory and Observation }\end{array}$ & Kodaikanal \\
\hline Nov $30-$ Dec 4 & 1999 & IAUS 199 & The Universe at Low Radio Frequencies & Pune \\
\hline Jan $23-27$ & 1995 & IAUC 154 & Solar and Interplanetary Transients & Pune \\
\hline$? ?$ & 1994 & ISYA 1994 & International School for Young Astronomers & Pune \\
\hline Aug $16-20$ & 1993 & APRIM & 6th Asian-Pacific Regional IAU Meeting & Pune \\
\hline Oct $10-13$ & 1990 & IAUC 132 & $\begin{array}{l}\text { Instability, Chaos and Predictability in Celestial } \\
\text { Mechanics and Stellar Dynamics }\end{array}$ & New Delhi \\
\hline Feb 1-? & 1987 & ISYA 1987 & International School for Young Astronomers & Patalia \\
\hline Dec $1-5$ & 1989 & IAUS 142 & Basic Plasma Processes on the Sun & Bangalore \\
\hline Dec $3-7$ & 1985 & IAUS 120 & Astrochemistry & Goa \\
\hline Dec $2-6$ & 1985 & IAUS 119 & Quasars & Bangalore \\
\hline Nov $13-16$ & 1985 & IAUC 91 & History of Oriental Astronomy & New Delhi \\
\hline Nov $10-15$ & 1985 & IAUC 87 & Hydrogen Deficient Stars and Related Objects & Mysore \\
\hline Nov $18-28$ & 1985 & IAU GS XIX & 19th IAU General Assembly & New Delhi \\
\hline Oct $6-$ Nov 29 & 1969 & ISYA 1969 & International School for Young Astronomers & Hyderabad \\
\hline Jan $9-18$ & 1967 & IAUC 14 & International Conference on Spectroscopy & Bombay \\
\hline
\end{tabular}

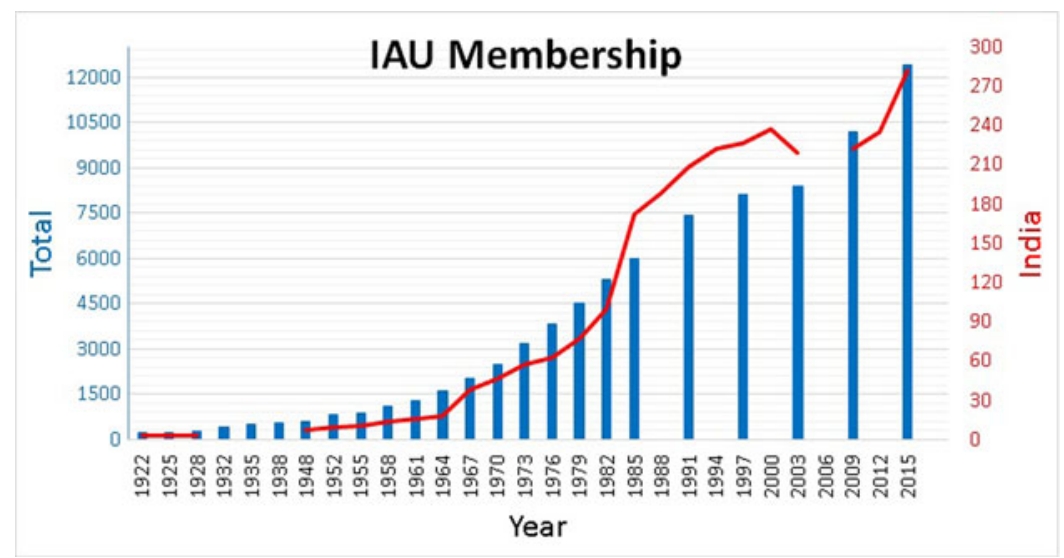

Figure 3. IAU Membership Growth - Total versus Indian Membership.

Table 2 lists the number of IAU Meetings held in India starting from IAUC XIV in Bombay in 1967. This too shows an increase in the last two decades. Finally, Fig. 3 shows the growth of Indian membership in the IAU. 


\section{Acknowledgements}

I thank John Hearnshaw for the invitation to speak at this symposium, the IAU for a Travel Grant and Dr Benvenuti and his team, especially Ms Madeleine Smith-Spanier, for providing some of the vital information which has gone into writing the paper.

I also thank Virginia Mills of The Royal Society and Christina Birdie, Librarian and Archivist at the Indian Institute of Astrophysics, Bangalore, for continuous help in digging up old documents, providing correct references and for putting up with my constant demands ungrudgingly.

\section{References}

Batten, A. H. 1986, The I.A.U. meeting in India, Journal of the Roy. Astron. Soc. Canada, 80,121

Fowler, A. 1922, (ed). IAU Transactions, Vol. 1

Oort, J. H. 1948, IAU Transactions, Vol. 7

Saha, M. N. 1955, Science and Culture, Vol. 21, 183-189

Sahni, S. K. and Tandon, P. N. 2017, Indian National Science Academies: Inspirational Journey Through 75 Years, New Delhi 